Acta Cryst. (2002). A58 (Supplement), C210

PROBING THE NATURE OF THE Co(III) ION IN COBALT CORRINOIDS: THE STRUCTURES OF SOME B12 DERIVATIVES WITH COORDINATED AMBIDENTATE NUCLEOPHILES

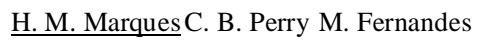

Molecular Sciences Institute, School of Chemistry, University of The Witwatersrand, Johannesburg, South Africa

$\mathrm{Co}(\mathrm{III})$ is the classic example of an inert d6 metal ion, yet it undergoes fast ligand exchange in the cobalt corrinoids. This suggests that $\mathrm{Co}$ (III) has some (labile) $\mathrm{Co}$ (II) character when coordinated in the equatorial plane by the macrocycle corrin. The nature of $\mathrm{Co}$ (III) is probed by examining the product of its reactions with amident nucleophiles. Based on these solid state observations, and our kinetics results, we suggest that $\mathrm{Co}$ (III) in the cobalamins does indeed have some $\mathrm{Co}$ (II) character.

Keywords: COBALT CORRINOIDS B12 AMBIDENTATE LIGANDS

Acta Cryst. (2002). A58 (Supplement), C210

\section{STRUCTURE AND MAGNETISM OF DICYANAMIDE} COORDINATION POLYMERS

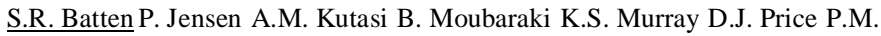
van der Werff

Monash University School of Chemistry School of Chemistry, PO Box 23 MONASH UNIVERSITY VICTORIA 3800 AUSTRALIA

Following the 1998 discovery [1] of long-range magnetic ordering in the $\alpha$ $\mathrm{M}(\mathrm{dca})_{2}$, dca $=$ dicyanamide, $\left\{\mathrm{N}(\mathrm{CN})_{2}\right\}^{-}$series of compunds, we have examined a large range of dca coordination polymers in an attempt to relate structure to magnetic properties. Direct correlations, however, are at present elusive. Long-range magnetic ordering has been found in structures containing bidentate dca, tridentate dca, rutile-like 3-D networks, self-penetrating 3-D networks, 2-D sheets of varying topologies, cation-templated anionic 2-D networks, and 1-D chains hydrogen bonded into layers. Conversely, many closely related structures show no long-range ordering.

References

[1] S.R. Batten, P. Jensen, B. Moubaraki, K.S. Murray, R. Robson, Chem. Commun., 1998, 439.

\section{Keywords: COORDINATION POLYMERS MAGNETISM} DICYANAMIDE
Acta Cryst. (2002). A58 (Supplement), C210

ASSEMBLY OF FUNCTIONAL SUPRAMOLECULAR SOLIDS FROM METAL AND ORGANIC BUILDING BLOCKS

M. P. Suh H. J. Choi J. W. Ko

Seoul National University School of Chemistry and Molecular Engineering

Sinlim-Dong, Kwanak-Gu SEOUL 151-747 SOUTH KOREA

Crystal engineering provides a useful paradigm for the design of metal-organic supramolecular networks with tunable properties by the choice of building blocks. The modular supramolecular networks might find applications to molecular adsorption and separation processes, ion-exchange, catalysis, sensor technology, and memory devices.

We have assembled a number of metal-organic supramolecular solids containing cavities and channels of various shapes and sizes by the selfassembly of metal and organic building blocks. In particular, we have employed macrocyclic complexes as metal building blocks since they provide fixed numbers of vacant coordination sites at the fixed positions, which enables the extending direction of the networks to be controllable.

The self-assembly of various macrocyclic complexes and 1,3,5tricarboxybenzene provides the open frameworks generating cavities and channels of effective diameter size $7 \AA-10 \AA$. The self-assembly of nickel(II) cyclam complex with a bigger organic building block, 1,3,5-tris[2-(4carboxyphenyl)-1-ethynyl]benzene results in 2D nets with honeycomb cavities of ca. $50 \AA$ size, but they are triply parallel interwoven to give rise to a thick 2D layer providing smaller triangular voids of dimension ca. $20 \AA$. The open frameworks manifest selective recognition and inclusion of guest molecules such as D-glucose, metal complexes, alcohols, and aromatic compounds. Some of them even show single-crystal-to-single-crystal conversions on guest removal, guest exchange, and chemical reactions.

Keywords: SELF ASSEMBLY, SUPRAMOLECULAR NETWORK, GUEST BINDING

Acta Cryst. (2002). A58 (Supplement), C210

NEW POLYMERIC ARCHITECTURES ASSEMBLED WITH TETRA(4-PYRIDYL)PORPHIRINE BUILDING BLOCKS

D. Proserpio $^{1}$ L. Carlucci ${ }^{2}$ G. Ciani ${ }^{1}$ F. Porta ${ }^{3}$

${ }^{1}$ Universita' Di Milano Dip. Di Chimica Strutturale E Stereochimica Inorganica Via Venezian 21 MILANO 20133 ITALY ${ }^{2}$ Dip. di Biologia Strutturale e Funzionale, Universita' dell'Insubria ${ }^{3}$ Dip. CIMA, Universita' di Milano

The crystal engineering of coordination frameworks, of potential interest as zeolite-like materials, requires the use of suitable building blocks. Among these much attention has been recently devoted to the networking ability of substituted porphirines and metallo-porphirinates (1), acting as tetradentate planar donor groups, that have been mainly reacted with metal dications. We report here on the polymeric products obtained from the reactions of tetra(4pyridyl)porphirine (TPPY) and Zn[tetra(4-pyridyl)porphirinate) (ZnTPPY) with different silver salts. With 1 we have obtained $1 \mathrm{D}$ polymeric linear chains in $[\mathrm{Ag}(\mathrm{TPPY})] \mathrm{NO}_{3}$ and 2-D layers of square grids in $\left[\mathrm{Ag}(\mathrm{TPPY}) \mathrm{CF}_{3} \mathrm{SO}_{3}\right]$. The reactions of ZnTPPY are more complex, due to the possible formation of direct bonds between the molecules of ZnTPPY in addition to those between ZnTPPY and silver ions, and have afforded a variety of interesting structural motifs. The products include different 2D layers: single layers of square meshes are present in $\left[\mathrm{Ag}_{2}(\mathrm{ZnTPPY})\left(\mathrm{CH}_{3} \mathrm{C}_{6} \mathrm{H}_{4} \mathrm{SO}_{3}\right)_{2}\right]$ and of hexagonal meshes in $\left[\mathrm{Ag}_{2}(\mathrm{ZnTPPY})\left(\mathrm{PF}_{6}\right)_{2}\right]$, while $\left[\mathrm{Ag}_{2}(\mathrm{ZnTPPY})_{2}\left(\mathrm{CF}_{3} \mathrm{SO}_{3}\right)_{2}\right]$ contains double layers of novel topology.

References

(1) I. Goldberg, Chem. Eur. J. (2000), 6, 3863.

Keywords: PORPHIRINE COORDINATION NETWORKS MIXED METALS 